\title{
Proinflammatory and anti-inflammatory cytokines in the CSF of patients with Alzheimer's disease and their correlation with cognitive decline
}

\author{
Ricardo Taipa a,b,c,*, Sofia P. das Neves ${ }^{\text {b,c }}$, Ana L. Sousa ${ }^{\text {a }}$, Joana Fernandes ${ }^{a}$, \\ Claudia Pinto $^{a}$, Ana P. Correia ${ }^{a}$, Ernestina Santos ${ }^{a}$, Pedro S. Pinto ${ }^{a}$, Paula Carneiro ${ }^{\mathrm{d}}$, \\ Patricio Costa ${ }^{\text {b,c }}$, Diana Santos ${ }^{\mathrm{e}, \mathrm{f}}$, Isabel Alonso ${ }^{\mathrm{e}, \mathrm{f}}$, Joana Palha ${ }^{\mathrm{b}, \mathrm{c}}$, \\ Fernanda Marques ${ }^{\text {b,c }}$, Sara Cavaco ${ }^{\text {a }}$, Nuno Sousa ${ }^{\text {b,c,g }}$ \\ a Department of Neurosciences, Centro Hospitalar do Porto, Porto, Portugal \\ ${ }^{\mathrm{b}}$ Life and Health Sciences Research Institute (ICVS), School of Medicine, University of Minho, Campus de Gualtar, Braga, Portugal \\ ' ICVS/3B's - PT Government Associate Laboratory, Braga, Guimarães, Portugal \\ ${ }^{\mathrm{d}}$ Immunology Department, Centro Hospitalar do Porto, Porto, Portugal \\ e i3S, Instituto de Investigação e Inovação em Saúde, Universidade do Porto, Porto, Portugal \\ ${ }^{\mathrm{f}}$ UnIGENe, Instituto de Biologia Molecular e Celular (IBMC), Porto, Portugal \\ ${ }^{g}$ Centro Clínico Académico (2CA), Braga, Portugal
}

\section{A R T I C L E I N F O}

\section{Article history:}

Received 6 July 2018

Received in revised form 28 December 2018

Accepted 30 December 2018

Available online 7 January 2019

\section{Keywords:}

Neuroinflammation

Alzheimer's disease

Cytokines

Disease progression

Cognition

Cerebrospinal fluid

\begin{abstract}
A B S T R A C T
Cumulative data suggest that neuroinflammation plays a prominent role in Alzheimer's disease (AD) pathogenesis. The purpose of this work was to assess if patients with AD present a specific cerebrospinal fluid (CSF) cytokine profile and if it correlates to disease progression. We determined the levels of 27 cytokines in CSF of patients with AD and compared them with patients with frontotemporal dementia and nondemented controls. In addition, we correlated the cytokine levels with cognitive status and disease progression after 12 months. Patients with AD had higher levels of proinflammatory and anti-inflammatory cytokines (eotaxin, interleukin [IL]-1ra, IL-4, IL-7, IL-8, IL-9, IL-10, IL-15, granulocyte colony-stimulating factor, monocyte chemotactic protein 1, platelet-derived growth factor, tumor necrosis factor alfa) compared to nondemented controls. There was a negative correlation between the disease progression and the levels of several cytokines (IL-1 $\beta$, IL-4, IL-6, IL-9, IL-17A, basic fibroblast growth factor, granulocyte colony-stimulating factor, granulocyte-macrophage colony-stimulating factor, interferon gamma, macrophage inflammatory proteins-1 $\beta$ ). To the best of our knowledge, this is the first study reporting a "protective" role of the upregulation of specific intrathecal cytokine levels in AD. This finding supports that a fine "rebalancing" of the immune system represents a new target in AD therapeutic approach.
\end{abstract}

(c) 2019 Elsevier Inc. All rights reserved.

\section{Background}

Alzheimer's disease $(A D)$ is characterized by intracellular neurofibrillary tangles (composed by aggregates of aberrantly phosphorylated tau protein) and extracellular deposits of amyloid$\beta(A \beta)$ that are accompanied by neuronal and synaptic loss and neuroinflammation (reactive astrocytes and microglia) (Cummings and Cummings, 2004; Heneka et al., 2015; Taipa et al., 2012). Inflammation associated to $\mathrm{AD}$ pathology has been extensively documented, and the study of proinflammatory cytokines as biomarkers for AD has gained strong interest (Wang et al., 2015).

\footnotetext{
* Corresponding author at: Neuropathology Unit, Department of Neurosciences, Centro Hospitalar do Porto - Hospital Santo António, Largo Prof. Abel Salazar, 4099001 Porto, Portugal. Tel.: +351 222077500x1620; fax: +351 222077500.

E-mail address: rtaipa.neuropat@chporto.min-saude.pt (R. Taipa).
}

Cytokines are small signaling proteins that are involved in nearly every aspect of neuroinflammation (Dinarello, 2007). Yet, the reports on cytokine levels in AD are contradictory or inconclusive (see reviews: [Bagyinszky et al., 2017; Brosseron et al., 2014; Zheng et al., 2016]). Still, there appears to be a trend for both proinflammatory (interleukin [IL]-1 $\beta$, IL-6, tumor necrosis factor alfa [TNF- $\alpha]$ ) and anti-inflammatory cytokines (IL-1ra, IL-10) to be elevated in the cerebrospinal fluid (CSF) and plasma of patients with AD (Brosseron et al., 2014; Zheng et al., 2016). Methodological differences and heterogeneity in patient collective characterization could explain the discrepancy between studies. Few studies provide detailed clinical data (disease severity, disease duration, or neuropsychological testing) or have a longitudinal design.

In addition, it remains to be solved whether it is the innate immunity that enhances $A \beta$ accumulation, thereby initiating or 
accelerating pathological cascades or if the neuroinflammation is important for protection and clearance of $A \beta$ toxic species (Taipa et al., 2016). Recent studies support the concept of a more complex interplay between innate immunity and the "proteinopathy" associated to neurodegeneration (Chakrabarty et al., 2015; GuillotSestier et al., 2015a,b). This is particularly true in the context of the sporadic or late-onset $\mathrm{AD}$, where the complexity of $\mathrm{AD}$ pathogenesis is particularly evident and clearly more distant from the simple assumption of a linear causality of the original amyloid hypothesis (Scheltens et al., 2016).

In this study, we evaluated the levels of 27 cytokines in CSF of patients with $\mathrm{AD}$ as compared with another neurodegenerative dementia, frontotemporal dementia (FTD), and nondemented (ND) controls. Detailed patients' clinical data were obtained at the baseline and after 1 year of follow-up. To establish the links with clinical symptomatology, we analyzed the correlation of cytokine levels with cognitive features and with disease progression at 1 year.

\section{Material and methods}

\subsection{Subjects}

Patients were prospectively enrolled from the dementia outpatient clinic of the Department of Neurology of Centro Hospitalar do Porto (CHP) between February 2013 and April 2017. All patients underwent a standard battery of examinations, including medical and family history, physical and neurological examination, screening laboratory tests, neuropsychological evaluation (including Mini-Mental State Examination, Dementia Rating Scale2, Auditory Verbal Learning Task, Benton visual Retention Test, Complex Rey Figure, Digit Span, Corsi Test, Judgment of Line Orientation, Trail Making Test, Wisconsin Card Sorting Test, Verbal fluency and Boston Naming Test, Hospital Anxiety and Depression Scale, and Neuropsychiatric Inventory), brain magnetic resonance image, and CSF analysis. The clinical history followed a structured interview, which included a systematic recording of changes in cognition and behavior. Neuropsychological assessment, magnetic resonance image acquisition, and lumbar puncture (LP) were performed within 4 weeks after first clinical visit.

The diagnosis of AD was established according to the recent NIAAA 2011 criteria (McKhann et al., 2011). The duration of symptoms had to be equal or less than 4 years. Due to the lack of established cutoff values for AD CSF biomarkers in our laboratory, the total tau/ $A \beta 42$ ratio of $>0.52$ was used to define a positive CSF profile for AD pathology (Duits et al., 2014). Patients with subjective memory complaints and pseudo-dementia who underwent study protocol were included as ND controls. A group of patients with FTD was included for comparison (Rascovsky et al., 2011). In addition, 4 cases from the Minho integrative neurosciences database biobank, with no history of inflammatory disorder or cognitive impairment, were added to the control group in the CSF studies. Patients with significant vascular brain damage were excluded (strategically placed and/or large vessel infarcts and/or white matter lesions setting a Fazekas scale $>2$ ). Exclusion criteria additionally included the presence of any chronic inflammatory disease and chronic use of steroidal anti-inflammatory drugs or immunosuppressive agents. In addition, a blood sample was taken in the same day of LP, and Creactive protein was measured to exclude systemic inflammation.

The study was approved by the ethical committee of CHP. All patients (or their surrogates) provided informed consent.

\subsection{Blood collection and CSF collection}

Blood and CSF collection was performed at CHP. Whole blood samples were allowed to sit at room temperature for a maximum of
30 minutes after collection. Separation of the clot was done by centrifugation at $3000 \mathrm{rpm}$ at room temperature for 15 minutes. CSF samples were obtained in polypropylene tubes by LP at the L4/ L5 or L3/L4 interspace. Serum and CSF samples were aliquoted, immediately frozen, and stored at $-80^{\circ} \mathrm{C}$ until analysis.

\subsection{A 442 , tau, and $p$-tau determination}

CSF A $\beta 42$, phospho tau (ptau), and total tau (htau) protein levels were determined using commercially available $A \beta 42$ (INNOTEST $\beta$ amyloid 1-42), htau (INNOTEST htau-Ag), ptau (INNOTEST phospho-tau 181P) ELISA assay kits (Innogenetics, Gent, Belgium) according to the manufacturer's instructions. Blood contamination of the CSF was excluded by cytochemical analysis.

\subsection{APOE genotyping}

Apolipoprotein E (APOE) genotyping was performed by polymerase chain reaction amplification of exon 4 with HotStarTaq Master Mix (Qiagen), followed by bidirectional direct sequencing with BigDye Terminator v1.1 Cycle Sequencing Kit (Applied Biosystems). Sequencing reactions were loaded on an ABI-PRISM 3130 XL Genetic Analyzer (Applied Biosystems) and analyzed with the SeqScape v.2.6 software. Genotypes for rs429358 and rs7412 were determined for each patient to determine the APOE alleles and the genotype for each patient. Allele E3, the most common, shows a cysteine at amino acid position 130 and arginine at position 176, according to NM_000041.3. Alleles E2 and E4 differ from E3 by single amino acid substitutions at positions 176 and 130, respectively [E2: p.(Arg158Cys); E4: p.(Cys112Arg)].

\subsection{Cytokines quantification}

Cytokines were measured using the Bio-Plex Pro Human Cytokine 27-Plex Immunoassay kit according to instructions from the manufacturer (Bio-Rad Laboratories, Hercules, CA, USA). These include basic fibroblast growth factor (FGF basic), eotaxin, granulocyte colony-stimulating factor (G-CSF), granulocytemacrophage colony-stimulating factor (GM-CSF), interferon gamma (IFN- $\gamma$ ), IL-1 $\beta$, IL-1ra, IL-2, IL-4, IL-5, IL-6, IL-7, IL-8, IL-9, IL10, IL-12 (p70), IL-13, IL-15, IL-17A, IFN- $\gamma$ inducible protein (IP-10), monocyte chemotactic protein 1 (MCP-1), macrophage inflammatory proteins (MIP)- $1 \alpha$, MIP- $1 \beta$, platelet-derived growth factor (PDGF-BB), TNF- $\alpha$, and vascular endothelial growth factor (VEGF) (cytokine list with biological role summary in Supplementary Material, Supplementary Table 1). Plates were read in a Bio Plex MAGPIX Multiplex Reader (Bio-Rad Laboratories), and data were analyzed using Bio-Plex Manager MP 6.1 (Bio-Rad Laboratories). All samples were quantified in duplicate, and a coefficient of variation lower than $30 \%$ was considered for sample inclusion in analysis, for each cytokine. Moreover, for the standard curves, a 4PL or 5PL regression was used; standards with coefficient of variation values higher than $30 \%$ were excluded. Concentration values below the lowest standard, or above the highest standard, extrapolated by the analysis software were also included in the statistical analysis. Three different plates were performed in different days, with cases from all groups represented (ND controls, AD and FTD, randomly assigned) in the 3 plates. The absolute values obtained were converted into $\mathrm{z}$ scores. This approach was applied to exclude different plates/days effect (Supplementary Material).

\subsection{Statistical analysis}

Descriptive statistics, including means, standard deviations, frequencies, and percentages were calculated. To compare the 
groups under analysis in the clinical and demographical variables, we performed a one-way ANOVA and $t$-test for quantitative measures and the $\chi^{2}$ test specifically for gender. According with the Levene's test for equality of variances, the Welch correction was applied if unequal variances were observed and the post hoc test was performed accordingly (Bonferroni for equal variances assumed and Games Howell for unequal variances). For the comparison of cytokines between groups, we performed one-way ANOVA or KruskalWallis according to the sample distribution (normal or nonnormal), and a post hoc test was performed accordingly (Bonferroni's and Dunn's multiple comparison test). According to the normality of the sample distribution, Pearson or Spearman's correlation coefficient was calculated to assess the relation between cytokines and cognitive data, cytokines and age, and cytokines and AD CSF biomarkers (ptau, htau and A $\beta 42$ ). Twenty-seven linear regressions were run considering each cytokine as dependent variables and sex, age, education, and APOE status as predictors. Unstandardized residuals from these regressions were correlated with cognitive data through Pearson's or Spearman's correlation coefficients. Finally, we performed receiver operating characteristic curves to assess the performance of each cytokine for diagnostic classification of patients. Data were analyzed using IBM SPSS Statistics software (version 25.0) and GraphPad Prism, version 6.01. A pvalue of less than 0.05 was considered statistically significant.

\section{Results}

\subsection{Characteristics of the sample}

Fifty-one patients met the diagnostic criteria of $\mathrm{AD}(\mathrm{n}=32 ; 21$ early onset $A D$ and 11 late onset $A D)$ or $\operatorname{FTD}(n=19)$. One AD case was excluded due to an elevated C-reactive protein in the day of the LP (respiratory infection) (Fig. 1). Nine subjects with subjective memory complaints, 4 cases with pseudo-dementia (minor depressive symptoms with cognitive complaints), and 4 additional cases from the Minho integrative neurosciences database biobank were used as noninflammatory and ND neurological controls. The CSF was collected in similar conditions in all groups. One AD case had pathological confirmation of AD with neocortical Lewy bodies, and 1 patient with $A D$ phenotype that was excluded based on negative CSF biomarkers had a pathological confirmation of an argyrophilic grain disease. Three cases of the FTD group had a genetic FTD form ( 2 with a progranulin disease-causing and one with C9orf72 hexanucleotide repeat expansion). Twenty-five cases of the AD group had APOE genotype determined, and 7 were heterozygous and 1 case homozygous for the $\varepsilon 4$ allele. The main demographic and clinical characteristics of the study groups are reported in Table 1.

There was an overrepresentation of male cases in the FTD group compared with ND and AD groups.

\subsection{Cytokine levels in the CSF}

The level of most cytokines was elevated in patients with $A D$ when compared with ND as illustrated in Fig. 2. Of interest, the level of cytokines in the FTD group appeared to be in an intermediate position.

The CSF levels were significantly different between groups (ND, patients with AD and FTD) in eotaxin, IL-1ra, IL-4, IL-7, IL-8, IL-9, IL10, IL-15, G-CSF, GM-CSF, MCP-1, PDGF-bb, TNF- $\alpha$, and VEGF. Post hoc testing showed that subjects with AD had significantly higher values than ND in all the previous listed cytokines, with exception of GM-CSF, MCP-1 and VEGF, where differences were between AD and FTD in the former and FTD and ND in the later. Post hoc testing additionally revealed differences between AD and FTD groups in IL15 (Fig. 2).

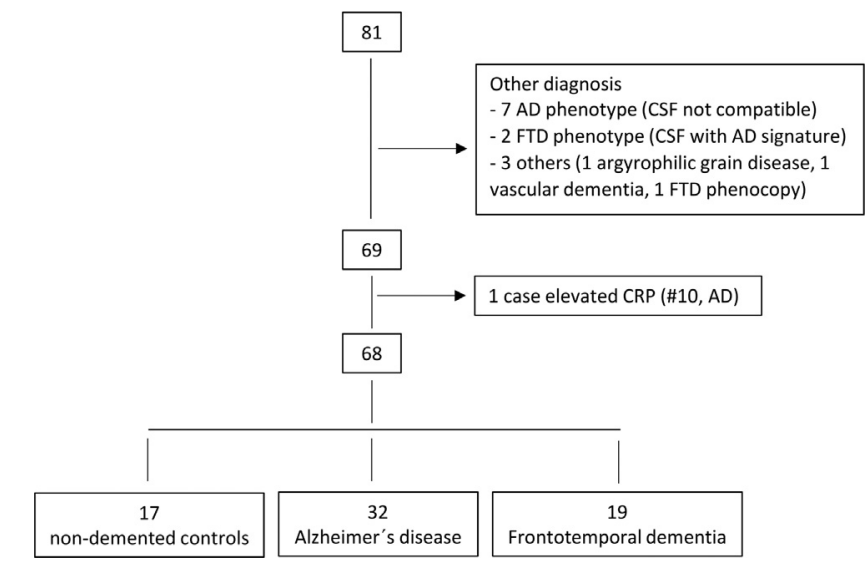

Fig. 1. Study enrollment flow chart. Abbreviations: AD, Alzheimer's disease; FTD, frontotemporal dementia; CRP, C-reactive protein; CSF, cerebrospinal fluid.

\subsection{Correlation between cytokines and cognitive characteristics and disease progression}

In the $\mathrm{AD}$ group, there were several inflammatory molecules that correlated positively with cognitive status (IL-1 ra, IL-4, IL-7, IL9, IL-10, IL-13, Eotaxin, G-CSF, and MIP-1 $\beta$ ) at the baseline (Table 2). Importantly, we found that several cytokines (IL-1 $\beta$, IL-2, IL-4, IL-5, IL-6, IL-9, IL-10, IL-12, IL-17A, eotaxin, FGF basic, G-CSF, GM-CSF, IFN- $\gamma$, MIP-1 $\beta$, PDGF-BB) correlated negatively with cognitive decline after 1 year (Table 2; Fig. 3). Because of the evidence of APOE isoforms modulation, particularly APOE $\varepsilon 4$ in neuroinflammation (Tai et al., 2015), the effect of APOE status (presence of $\varepsilon 4$ polymorphism) was excluded from the analysis, together with demographic and education variables; importantly, most of the correlations with cognitive decline remained significant (Table 2; Fig. 3).

In the FTD group, there was a significant negative correlation between IL-1ra cytokine and cognitive status at the baseline $(r=-0.505 ; p=0.039)$. In addition, IL-7 levels correlated positively with disease progression $(r=0.642 ; p=0.024)$.

In the control group, there was no correlation between any of the molecules and cognitive status at the baseline.

\subsection{Correlation to age}

When considering all subjects, there was a positive correlation between age and MCP-1 levels ( $r=0.319, p=0.009$ ) (Fig. 4A). Multiple regression linear analysis including age and diagnostic group showed that both correlated with MCP-1 levels $[\mathrm{F}(2,66)=$ $7,487, p<0.01]$. In the AD and FTD groups, there was a significant positive correlation with MCP- $1(r=0.425, p=0.015$ and $r=0.573$, $p=0.013$, respectively) (Fig. 4B and C). No significant correlation was found in the control group.

\subsection{Correlation with Alzheimer's disease biomarkers}

When considering the whole sample, we found a positive weak correlation between IL-1ra, IL-2, IL-4, IL-8, IL-9, IL-10, IL-15, G-CSF, GM-CSF, or TNF- $\alpha$ and at least one tau biomarker (ptau and/or htau). Conversely, a negative weak correlation emerged between A $\beta 42$ and IL-1ra, IL-8, and G-CSF. When considering the AD group, there was only a positive weak correlation between IL- 2 and both ptau and htau, between IL-15 and htau, and between both IL-5 and TNF- $\alpha$ and $A \beta 42$. In the FTD group, there was a weak positive correlation between IL-10 and ptau (Supplementary Table 2). 
Table 1

Demographic and clinical information

\begin{tabular}{|c|c|c|c|c|}
\hline & Nondemented controls $(n=17)$ & $\mathrm{AD}(\mathrm{n}=32)$ & $\operatorname{FTD}(\mathrm{n}=19)$ & Statistical test result \\
\hline $\operatorname{Sex}(M: F)$ & $6: 11$ & $12: 20$ & $16: 3$ & $\mathrm{X}^{2}(2, \mathrm{n}=68)=12.2 ; p<0.01$ \\
\hline Age & $60.4 \pm 7.9$ & $62.7 \pm 8.1$ & $64.1 \pm 7.7$ & $\mathrm{~F}(2,64)=0.936 ; p=0.398$ \\
\hline Education (y) & $6.4 \pm 3.5$ & $6.6 \pm 4.5$ & $4.7 \pm 1.6$ & $\mathrm{~F}(2,28.4)=3.164 ; p=0.057$ \\
\hline MMSE & $28.2 \pm 1.9$ & $18.2 \pm 6.6^{\mathrm{a}, \mathrm{b}}$ & $23.2 \pm 4.3$ & $\mathrm{~F}(2,26.0)=30.135 ; p<0.001$ \\
\hline DRS-2 (z score) & $-1.1 \pm 1.6$ & $-5.5 \pm 2.8^{\mathrm{a}}$ & $-5.0 \pm 4.1^{\mathrm{c}}$ & $\mathrm{F}(2,57)=9.429 ; p<0.001$ \\
\hline CSF ptau & $50.3 \pm 13.2$ & $88.3 \pm 29.4^{\mathrm{a}, \mathrm{d}}$ & $35.8 \pm 12.6$ & $\mathrm{~F}(2,36.1)=38.243 ; p<0.001$ \\
\hline CSF htau & $233.3 \pm 64.3$ & $669.4 \pm 323.8^{\mathrm{a}, \mathrm{d}}$ & $233.4 \pm 129.2$ & $\mathrm{~F}(2,39.4)=26.634 ; p<0.001$ \\
\hline CSF A $\beta 42$ & $1225.9 \pm 222.7$ & $531.8 \pm 108.4^{\mathrm{a}, \mathrm{d}}$ & $914.6 \pm 246.7^{\mathrm{a}}$ & $\mathrm{F}(2,22.8)=70.182 ; p<0.001$ \\
\hline
\end{tabular}

Values are given as the mean and standard deviations.

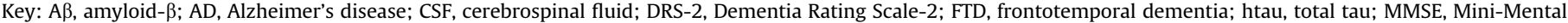
State Examination; ptau, phosphorylated tau; y, years.

a $p<0.001$ versus ND.

b $p<0.05$ versus FTD.

c $p<0.01$ versus ND.

d $p<0.001$ versus FTD.

\subsection{Performance of cytokines for diagnostic classification}

We performed receiver operating characteristic curves for each cytokine to assess the prediction ability for the diagnosis. Sixtyeight cases were included (AD, FTD, and nondemented controls); the gold standard was the diagnosis of AD. A significant result was obtained for IL-1ra, G-CSF, IL-7, IL-8, IL-10, and IL-15 (Supplementary Table 3 ). The higher area under the curve was obtained for IL-1ra (AUC $=0.82)$.

\section{Discussion}

Despite the ongoing controversy about the role of neuroinflammation in the disease-initiating mechanism, it is now widely accepted that the activation of the immune system accompanies and contributes to the pathogenesis of AD (Heppner et al., 2015; Taipa et al., 2018). The notion that failure of the innate immune system to clear $A \beta$, rather than overproduction of the peptides, as the etiologic mechanism in sporadic $A D$ has been proposed (Mawuenyega et al., 2010). In a simplistic view, the innate immune cells (resident microglia and peripheral mononuclear phagocytes) lose their capacity to restrict cerebral $A \beta$ accumulation and switch into a pathological chronic activated state (Heneka et al., 2015), with altered production of cytokines (Sochocka et al., 2017) that becomes evident in brain tissue and in the CSF (Blennow et al., 2010). This study supports the concept that inflammatory dysregulation is associated to neurodegenerative dementias, particularly in AD.

Regardless of conflicting data in the literature, our results support the existence of an upregulation of both proinflammatory and anti-inflammatory cytokines in the CSF of patients with $\mathrm{AD}$ (Brosseron et al., 2014). More relevant, we found herein that the cognitive status in subjects with $\mathrm{AD}$ correlated positively with proinflammatory and anti-inflammatory molecules, supporting the notion that changes of the inflammatory profile in the CSF reflect a relevant phenomenon in the pathophysiology of the disease. In addition, we found a negative correlation between disease progression at 12 months and the levels of several cytokines, particularly proinflammatory cytokines, which suggests that a stronger inflammatory response leads to a better clinical progression. Contrary to our findings, some studies reported faster disease progression in association with higher levels of some proinflammatory cytokines, namely eotaxin (CCL2) in prodromal AD (Westin et al., 2012). However, in vivo imaging studies showed that microglia activation was positively correlated with Mini-Mental State Examination scores in patients with $\mathrm{AD}$, and that patients with $\mathrm{AD}$ with slow decline had higher translocator protein-binding, a marker of microglial activation (Hamelin et al., 2016). More recently, the same group showed in a large cohort of 52 patients with AD that higher initial 18F-DPA-714 binding (a second generation translocator protein-binding) is associated with better clinical prognosis after a 2-year follow-up (Hamelin et al., 2018). These findings are in agreement with our results, strengthening the concept of a dynamic process that can have different consequences (protection vs injury) depending on the time and stage of disease.

The association of elevated CSF levels of important proinflammatory cytokines, such as IL- $1 \beta$, IL- 6 , and IFN- $\gamma$, with better clinical prognosis after 1 year highlights the importance of an integrative analysis of the AD-associated neuroinflammation. This is also important regarding the recent view that microglia states are not clearly divided between proinflammatory M1 phenotype and a neuroprotective M2 phenotype but can assume a continuum of activation states characterized by expression of intersecting markers (Guillot-Sestier et al., 2015a, b). The balance of proinflammatory and neuroprotective microglia activation is highly complex, especially in $\mathrm{AD}$, in which microglia may express mixed activation phenotypes (Hamelin et al., 2018; Minett et al., 2016). Our results are in line with the perspective that inflammation in the context of $\mathrm{AD}$ is not exclusively detrimental or beneficial but has to be fine-tuned (Michaud and Rivest, 2015). This relationship needs further studies, analyzing the pattern of the different inflammatory markers in different time points of the disease. Another indication of this dynamic change of cytokines throughout the disease course is suggested by their relationship with amyloid and tau biomarkers. In the whole sample, we found a weak positive correlation between 12 of the 27 cytokines with tau markers and a weak negative correlation between 6 of them with $A \beta 42$. Most of these associations are not present when we consider only the patients with AD or FTD. Suarez-Calvet et al. have demonstrated, in a cohort of asymptomatic familial AD mutation carriers, that CSF sTREM2 begins to rise only after amyloid deposition and tau-related changes occur but before symptoms emerge (Suárez-Calvet et al., 2016). Another recent study in cognitively healthy patients has shown a dynamic pattern of cytokine levels according to the amyloid (A) and tau (T) status of patients (Meyer et al., 2018). Several CSF inflammation markers showed a reduction from stage $0(\mathrm{~A}-\mathrm{T}-)$ to stage $1(\mathrm{~A}+\mathrm{T}-)$, followed by a sharp increase in stage $2(\mathrm{~A}+\mathrm{T}+)$. The decrease from stage $0-1$ was significant for IL12p40, IL12p70, IL15, and IL18; higher levels in stage 2 than stage 0 were found for ICAM1 and VCAM1. These findings are in line with the upregulation of CSF cytokines levels in the $\mathrm{AD}$ group compared with the nondemented controls (A-T-). Although no correlation was found between CSF inflammatory markers and amyloid or tau in patients with mild to moderate $\mathrm{AD}$ (in whom amyloid deposition and tau-related changes are already established), cytokines levels had impact in disease progression in our cohort. A longitudinal evaluation would allow a better understanding of the inflammatory marker's role and their relationship 

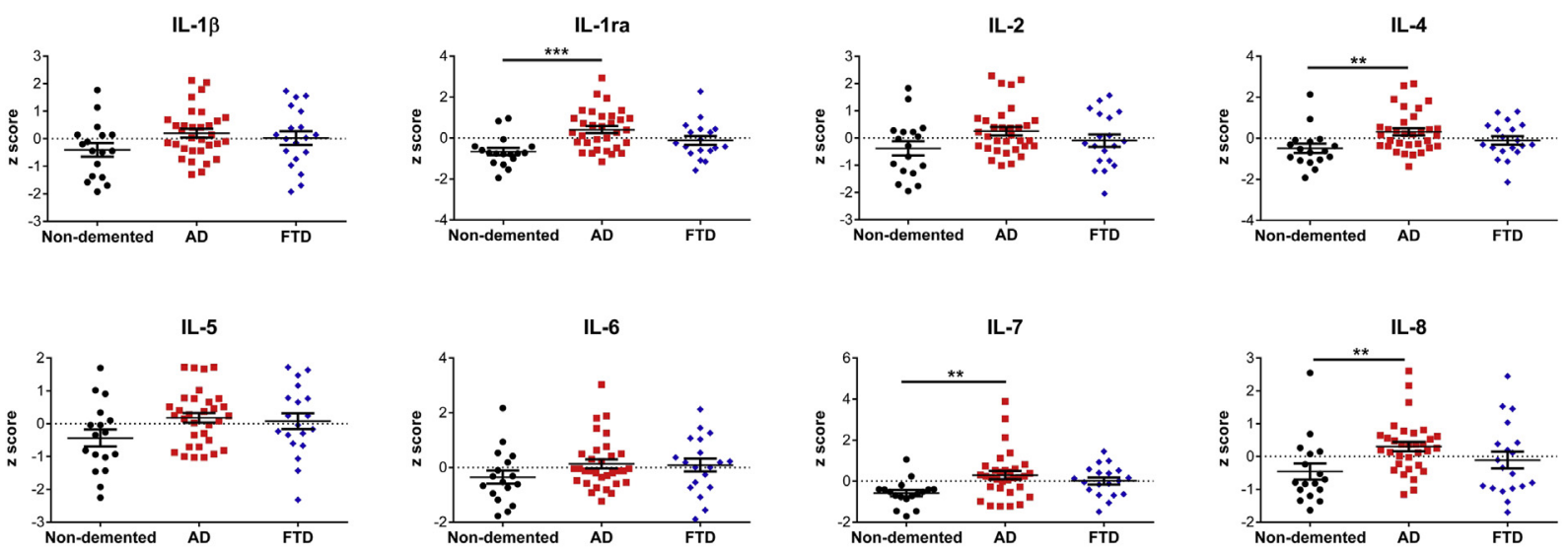

IL-9
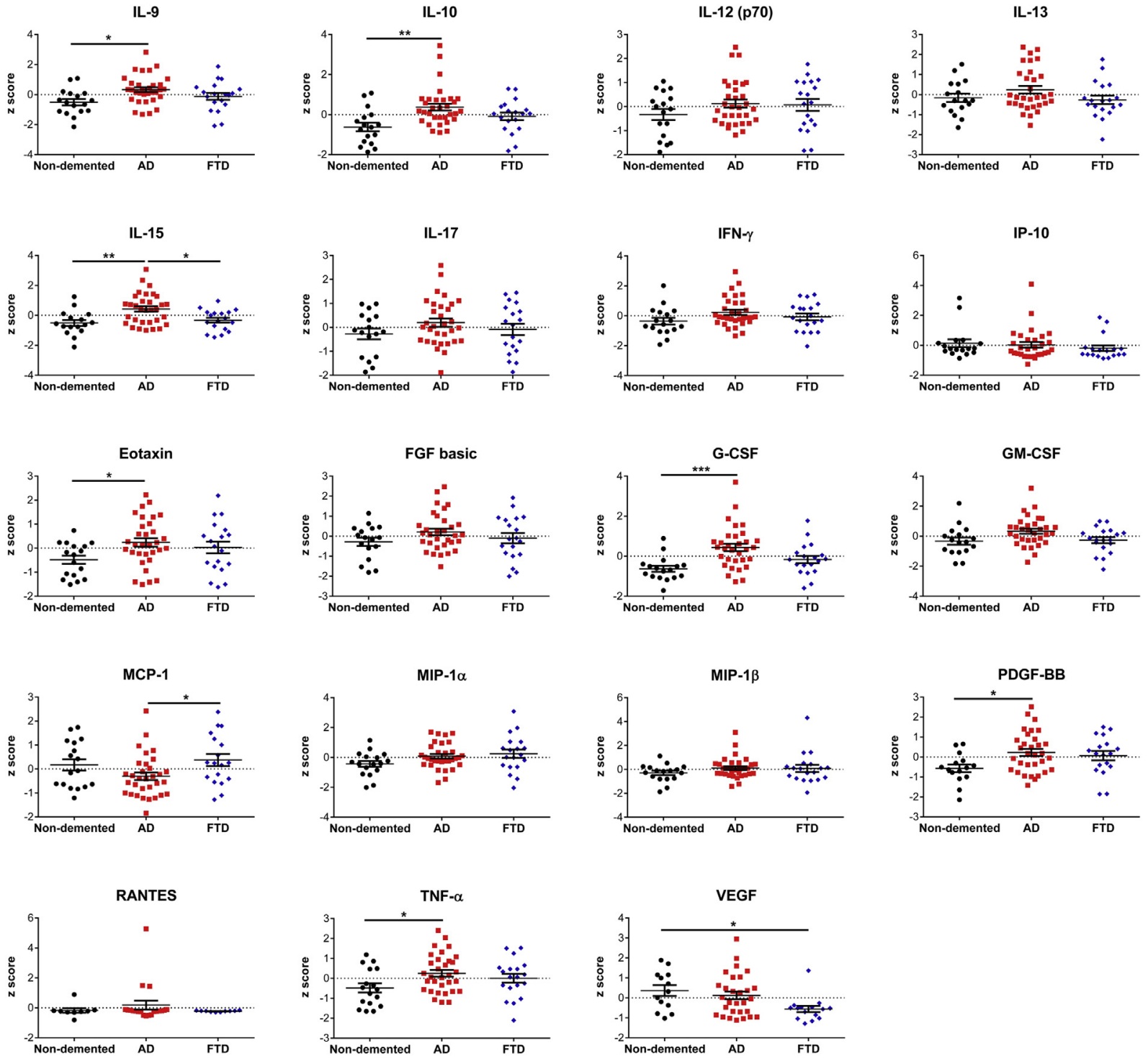

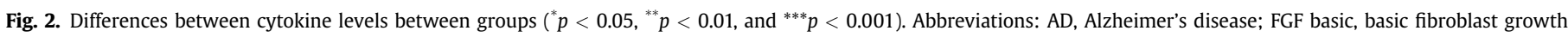

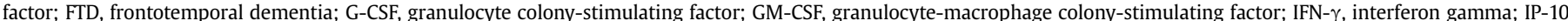

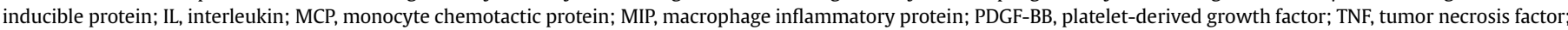
VEGF, vascular endothelial growth factor. 
Table 2

Correlation between cytokine levels and cognitive status (DRS-2), and cytokine levels and cognitive decline at 1 years in the AD group

\begin{tabular}{|c|c|c|c|c|}
\hline Cytokines & DRS-2 baseline & DRS-2 (T1-T2) & DRS-2 baseline ${ }^{c}$ & DRS-2 $(\mathrm{T} 1-\mathrm{T} 2)^{\mathrm{C}}$ \\
\hline IL-1 $\beta$ & 0.283 & $-0.556^{b}$ & 0.117 & $-0.576^{\mathrm{b}}$ \\
\hline IL-1ra & $0.385^{a}$ & -0.31 & 0.242 & -0.177 \\
\hline IL-2 & 0.197 & $-0.539^{b}$ & -0.220 & -0.440 \\
\hline IL-4 & $0.433^{\mathrm{a}}$ & $-0.467^{a}$ & 0.033 & $-0.507^{a}$ \\
\hline IL-5 & 0.321 & $-0.442^{\mathrm{a}}$ & 0.211 & -0.365 \\
\hline IL-6 & $0.381^{\mathrm{a}}$ & $-0.532^{b}$ & 0.112 & $-0.553^{a}$ \\
\hline IL-7 & $0.482^{b}$ & -0.308 & 0.415 & -0.367 \\
\hline IL-9 & $0.446^{\mathrm{a}}$ & $-\mathbf{0 . 6 1 5}^{\mathrm{b}}$ & 0.267 & $-0.578^{b}$ \\
\hline IL-10 & $0.475^{b}$ & $-0.436^{\mathrm{a}}$ & 0.193 & -0.376 \\
\hline IL-12 & 0.294 & $-0.432^{\mathrm{a}}$ & 0.107 & -0.391 \\
\hline IL-13 & $0.449^{a}$ & -0.429 & 0.394 & -0.277 \\
\hline IL-17 & 0.335 & $-0.568^{b}$ & 0.205 & $-0.577^{b}$ \\
\hline Eotaxin & $0.381^{\mathrm{a}}$ & $-0.415^{a}$ & 0.373 & -0.395 \\
\hline FGF basic & 0.185 & $-0.644^{b}$ & 0.051 & $-0.664^{b}$ \\
\hline G-CSF & 0.348 & $-0.575^{b}$ & 0.174 & $-0.521^{\mathrm{a}}$ \\
\hline GM-CSF & 0.172 & $-0.476^{a}$ & -0.062 & $-0.479^{a}$ \\
\hline IFN- $\gamma$ & 0.319 & $-0.452^{\mathrm{a}}$ & -0.138 & $-0.495^{a}$ \\
\hline MIP-1 $\beta$ & $0.371^{\mathrm{a}}$ & $-0.511^{a}$ & $0.429^{a}$ & $-0.577^{b}$ \\
\hline PDGF-BB & 0.339 & $-0.471^{\mathrm{a}}$ & 0.311 & -0.424 \\
\hline
\end{tabular}

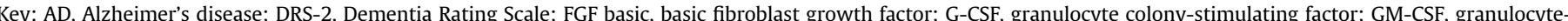

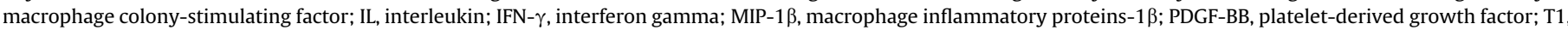
first neuropsychological evaluation; T2, second neuropsychological evaluation (12 months later).

Bolded values represents the results with statistical significance.

a $p<0.05$.

b $p<0.01$ (Pearson or Spearman's correlation).

c Controlling for APOE status, sex, age, and education.

with disease pathogenesis in $\mathrm{AD}$ and other neurodegenerative diseases.

Recently, genetic studies also found that immune dysfunction may play a role in the pathophysiology of FTD (Broce et al., 2018). Galimberti et al., 2015, using a similar methodological approach to
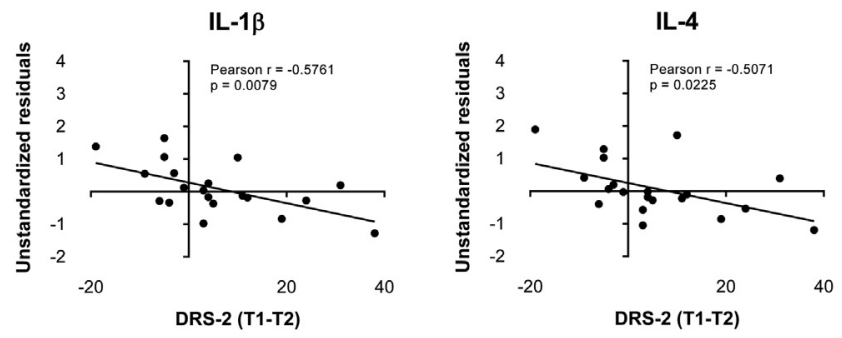

IL-17A
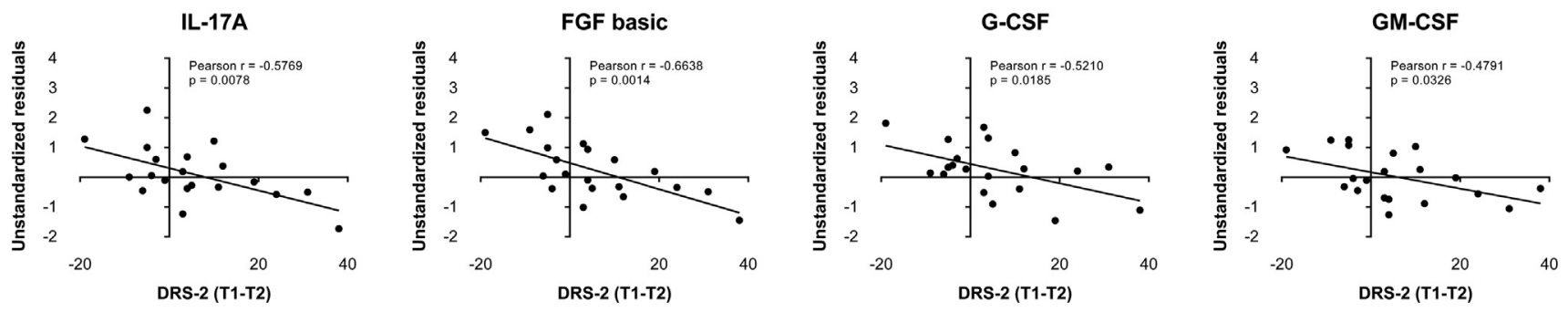

the one herein described, found elevated levels of MCP-1 in the CSF of patients with sporadic FTD. Despite a trend for higher values, we did not find the same difference. Moreover, comparing to AD, CSF inflammatory changes are less prominent in FTD cases. Increased intrathecal production of both proinflammatory and anti-
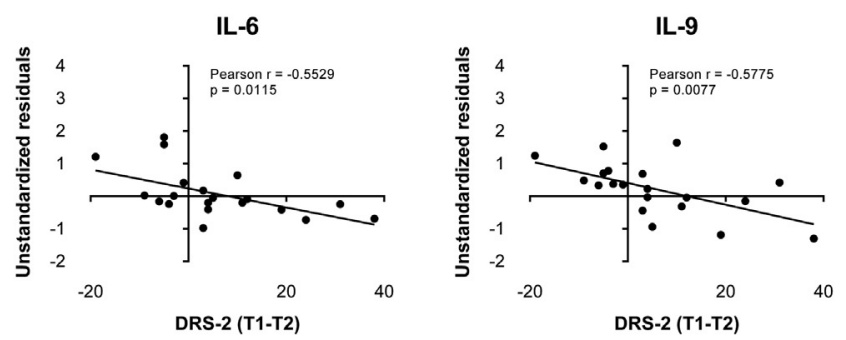
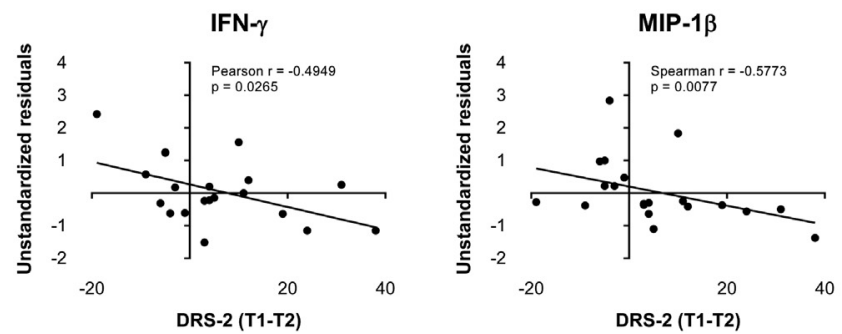

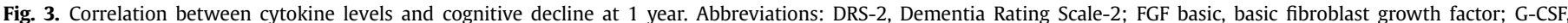

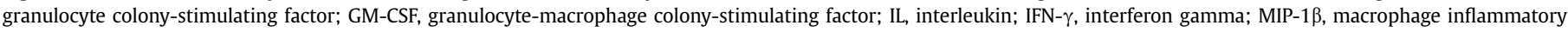
proteins- $1 \beta$. 
A

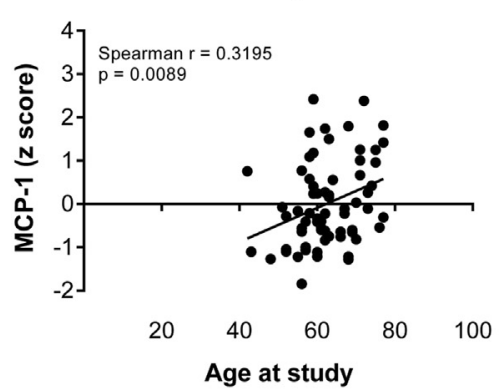

B

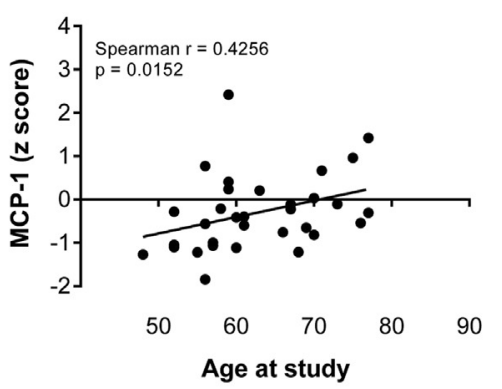

C

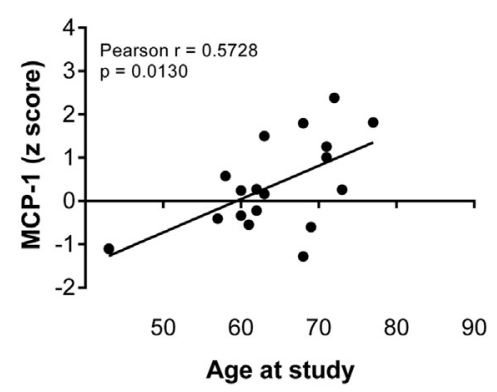

Fig. 4. Correlation between age and MCP-1 in AD and FTD. Abbreviations: AD, Alzheimer's disease; FTD, frontotemporal dementia; MCP-1, monocyte chemotactic protein 1.

inflammatory cytokines have been described in FTD compared to healthy controls (Galimberti et al., 2006b; Rentzos et al., 2006; Sjogren et al., 2004) and, similarly to our results, no differences were found when compared to AD. Differently from our findings, a previous study found that both patients with AD and FTD had elevated IL-15 concentrations compared with patients with noninflammatory neurological disorders (Rentzos et al., 2006). In the FTD group, the association to cognition was not so apparent as in the AD group. Remarkably, there was a negative association with cognitive status at the baseline with an anti-inflammatory cytokine (IL-1ra) and a positive association with disease progression with a proinflammatory cytokine (IL-7). It is relevant to mention that FTD refers to a clinical, genetic, and pathological heterogeneous group of disorders (Taipa et al., 2012). In addition, the neuropsychological testing used was not specifically designed to FTD clinical characteristics and, consequently, subtle or more specific cognitive decline could have been missed. Cytokine CSF dysregulation seems to be a common feature in AD and FTD. The better understanding on how it relates to cognitive function may require separating this entity in subgroups (FTLD-TDP, FTLD-tau), and tools assessing disease severity in specific domains, such as frontal system functions, should be used. We found the same correlation of MCP-1 with aging in FTD and AD groups previously reported (Galimberti et al., 2006a, 2015). Age-associated dysregulation of neuroimmune system and/or ageassociated neuroinflammation can represent a common pathway for neurodegenerative disorders, but specific disease characteristics seem to be present and modeling neuroinflammatory response.

Finally, we tested the use of cytokines as prediction tools for the AD diagnosis. We found significant results for 6 cytokines, with the best accuracy with IL-1ra (AUC $=0.82$ ). Their use as biomarkers, however, would have to be tested in larger and independent samples. The dynamic nature of cytokines in $\mathrm{AD}$ and the fact that currently used $\mathrm{AD}$ markers have excellent sensitivity and specificity makes them unlikely candidates as diagnostic tools (Dubois et al., 2014).

Our study has some limitations; namely, the small sample size and the control group (noninflammatory neurological controls (Teunissen et al., 2013) and not truly "healthy nondemented" controls). However, the patients have robust clinical diagnoses and follow-up periods. Serum analysis would also be important to mirror systemic inflammatory activity, particularly taking into account the suggested communication of the immune status between periphery and the central nervous system (Wang et al., 2017).

\section{Conclusion}

In summary, this study supports a proinflammatory and antiinflammatory immune dysregulation in AD. Furthermore, to the best of our knowledge, this is the first study reporting a "protective" role of cytokine levels in CSF. Our findings support the recent lines of evidence theorizing that "rebalancing" activation of the innate immune system, as opposed to shutting it off completely, represents a new AD therapeutic approach.

\section{Disclosure statement}

The authors declare that they have no competing interests.

\section{Acknowledgements}

The authors would like to acknowledge Aurora Rodrigues and Paulo Brochado for excellent technical assistance. The authors would also like to thank José Ferreira for the help in editing the article figures.

The authors acknowledge the Portuguese Brain Bank for the pathological examination of the patient included in the study.

Funding: The work at ICVS/3B's has been developed under the scope of the project NORTE-01-0145-FEDER-000013, supported by the Northern Portugal Regional Operational Program (NORTE, 2020), under the Portugal 2020 Partnership Agreement, through the European Regional Development Fund (FEDER) and funded by FEDER funds through the Competitiveness Factors Operational Program (COMPETE) and by National funds, through the Foundation for Science and Technology (FCT), under the scope of the project POCI-01-0145-FEDER-007038. The work at Centro Hospitalar do Porto (CHP) work was funded by "Bolsa para Investigação" of Departamento de Ensino Formação e Investigação (DEFI) do CHP. S.P. das Neves is a recipient of a PhD fellowship with the reference PD/BD/114120/2015, from POCH through FCT National Funds.

The study was approved by the ethical committee of CHP. All patients (or their surrogates) provided informed consent.

\section{Appendix A. Supplementary data}

Supplementary data associated with this article can be found, in the online version, at https://doi.org/10.1016/j.neurobiolaging.2018. 12.019.

\section{References}

Bagyinszky, E., Giau, V.V., Shim, K., Suk, K., An, S.S.A., Kim, S., 2017. Role of inflammatory molecules in the Alzheimer's disease progression and diagnosis. J. Neurol. Sci. 376, 242-254.

Blennow, K., Hampel, H., Weiner, M., Zetterberg, H., 2010. Cerebrospinal fluid and plasma biomarkers in Alzheimer disease. Nat. Rev. Neurol. 6, 131-144.

Broce, I., Karch, C.M., Wen, N., Fan, C.C., Wang, Y., Hong Tan, C., Kouri, N., Ross, O.A. Höglinger, G.U., Muller, U., Hardy, J., Momeni, P., Hess, C.P., Dillon, W.P. Miller, Z.A., Bonham, L.W., Rabinovici, G.D., Rosen, H.J., Schellenberg, G.D. Franke, A., Karlsen, T.H., Veldink, J.H., Ferrari, R., Yokoyama, J.S., Miller, B.L. Andreassen, O.A., Dale, A.M., Desikan, R.S., Sugrue, L.P., 2018. Immune-related genetic enrichment in frontotemporal dementia: an analysis of genome-wide association studies. PLoS Med. 15, e1002487. 
Brosseron, F., Krauthausen, M., Kummer, M., Heneka, M.T., 2014. Body fluid cytokine levels in mild cognitive impairment and Alzheimer's disease: a comparative overview. Mol. Neurobiol. 50, 534-544.

Chakrabarty, P., Li, A., Ceballos-Diaz, C., Eddy, J.A., Funk, C.C., Moore, B., DiNunno, N., Rosario, A.M., Cruz, P.E., Verbeeck, C., Sacino, A., Nix, S., Janus, C., Price, N.D., Das, P., Golde, T.E., 2015. IL-10 alters immunoproteostasis in APP mice, increasing plaque burden and worsening cognitive behavior. Neuron 85, 519-533.

Cummings, J.L., Cummings, J.L., 2004. Alzheimer's disease. N. Engl. J. Med. 351, 56-67.

Dinarello, C.A., 2007. Historical insights into cytokines. Eur. J. Immunol. 37 (Suppl 1), S34-S45.

Dubois, B., Feldman, H.H., Jacova, C., Hampel, H., Molinuevo, J.L., Blennow, K., DeKosky, S.T., Gauthier, S., Selkoe, D., Bateman, R., Cappa, S., Crutch, S., Engelborghs, S., Frisoni, G.B., Fox, N.C., Galasko, D., Habert, M.-O., Jicha, G.A., Nordberg, A., Pasquier, F., Rabinovici, G., Robert, P., Rowe, C., Salloway, S., Sarazin, M., Epelbaum, S., de Souza, L.C., Vellas, B., Visser, P.J., Schneider, L., Stern, Y., Scheltens, P., Cummings, J.L., 2014. Advancing research diagnostic criteria for Alzheimer's disease: the IWG-2 criteria. Lancet Neurol. 13, 614-629.

Duits, F.H., Teunissen, C.E., Bouwman, F.H., Visser, P.-J., Mattsson, N., Zetterberg, H., Blennow, K., Hansson, O., Minthon, L., Andreasen, N., Marcusson, J., Wallin, A., Rikkert, M.O., Tsolaki, M., Parnetti, L., Herukka, S.-K., Hampel, H., De Leon, M.J., Schröder, J., Aarsland, D., Blankenstein, M.A., Scheltens, P., van der Flier, W.M., 2014. The cerebrospinal fluid "Alzheimer profile": easily said, but what does it mean? Alzheimers Dement. 10, 713-723.e2.

Galimberti, D., Bonsi, R., Fenoglio, C., Serpente, M., Cioffi, S.M.G., Fumagalli, G., Arighi, A., Ghezzi, L., Arcaro, M., Mercurio, M., Rotondo, E., Scarpini, E., 2015. Inflammatory molecules in frontotemporal dementia: cerebrospinal fluid signature of progranulin mutation carriers. Brain Behav. Immun. 49, 182-187.

Galimberti, D., Schoonenboom, N., Scheltens, P., Fenoglio, C., Bouwman, F., Venturelli, E., Guidi, I., Blankenstein, M.A., Bresolin, N., Scarpini, E., 2006a. Intrathecal chemokine synthesis in mild cognitive impairment and Alzheimer disease. Arch. Neurol. 63, 538.

Galimberti, D., Schoonenboom, N., Scheltens, P., Fenoglio, C., Venturelli, E., Pijnenburg, Y.A.L., Bresolin, N., Scarpini, E., 2006b. Intrathecal chemokine levels in Alzheimer disease and frontotemporal lobar degeneration. Neurology 66, 146-147.

Guillot-Sestier, M.-V., Doty, K.R., Gate, D., Rodriguez, J., Leung, B.P., Rezai-Zadeh, K., Town, T., 2015a. Il10 deficiency rebalances innate immunity to mitigate Alzheimer-like pathology. Neuron 85, 534-548.

Guillot-Sestier, M.V., Doty, K.R., Town, T., 2015b. Innate immunity fights Alzheimer's disease. Trends Neurosci. 38, 674-681.

Hamelin, L., Lagarde, J., Dorothée, G., Leroy, C., Labit, M., Comley, R.A., de Souza, L.C., Corne, H., Dauphinot, L., Bertoux, M., Dubois, B., Gervais, P., Colliot, O., Potier, M.C., Bottlaender, M., Sarazin, M., Clinical IMABio3 Team, 2016. Early and protective microglial activation in Alzheimer's disease: a prospective study using 18F-DPA-714 PET imaging. Brain 139, 1252-1264.

Hamelin, L., Lagarde, J., Dorothée, G., Potier, M.C., Corlier, F., Kuhnast, B., Caillé, F., Dubois, B., Fillon, L., Chupin, M., Bottlaender, M., Sarazin, M., 2018. Distinct dynamic profiles of microglial activation are associated with progression of Alzheimer's disease. Brain 141, 1855-1870.

Heneka, M.T., Carson, M.J., El Khoury, J., Landreth, G.E., Brosseron, F., Feinstein, D.L., Jacobs, A.H., Wyss-Coray, T., Vitorica, J., Ransohoff, R.M., Herrup, K., Frautschy, S.A., Finsen, B., Brown, G.C., Verkhratsky, A., Yamanaka, K., Koistinaho, J., Latz, E., Halle, A., Petzold, G.C., Town, T., Morgan, D., Shinohara, M.L., Perry, V.H., Holmes, C., Bazan, N.G., Brooks, D.J., Hunot, S., Joseph, B., Deigendesch, N., Garaschuk, O., Boddeke, E., Dinarello, C.A., Breitner, J.C., Cole, G.M., Golenbock, D.T., Kummer, M.P., Khoury, J. El, Landreth, G.E., Brosseron, F., Feinstein, D.L., Jacobs, A.H., Wyss-Coray, T., Vitorica, J., Ransohoff, R.M., Herrup, K., Frautschy, S.A., Finsen, B., Brown, G.C., Verkhratsky, A., Yamanaka, K., Koistinaho, J., Latz, E., Halle, A., Petzold, G.C., Town, T., Morgan, D., Shinohara, M.L., Perry, V.H., Holmes, C., Bazan, N.G., Brooks, D.J., Hunot, S., Joseph, B., Deigendesch, N., Garaschuk, O., Boddeke, E., Dinarello, C.A., Breitner, J.C., Cole, G.M., Golenbock, D.T., Kummer, M.P., El Khoury, J., Landreth, G.E., Brosseron, F., Feinstein, D.L., Jacobs, A.H., Wyss-Coray, T., Vitorica, J., Ransohoff, R.M., Herrup, K., Frautschy, S.A., Finsen, B., Brown, G.C., Verkhratsky, A., Yamanaka, K., Koistinaho, J., Latz, E., Halle, A., Petzold, G.C., Town, T., Morgan, D., Shinohara, M.L., Perry, V.H., Holmes, C., Bazan, N.G., Brooks, D.J., Hunot, S., Joseph, B., Deigendesch, N., Garaschuk, O., Boddeke, E., Dinarello, C.A., Breitner, J.C., Cole, G.M., Golenbock, D.T., Kummer, M.P., 2015. Neuroinflammation in Alzheimer's disease. Lancet Neurol. 14, 388-405.

Heppner, F.L., Ransohoff, R.M., Becher, B., 2015. Immune attack: the role of inflammation in Alzheimer disease. Nat. Rev. Neurosci. 16, 358-372.

Mawuenyega, K.G., Sigurdson, W., Ovod, V., Munsell, L., Kasten, T., Morris, J.C., Yarasheski, K.E., Bateman, R.J., 2010. Decreased clearance of CNS -amyloid in Alzheimer's disease. Science 330, 1774.
McKhann, G.M., Knopman, D.S., Chertkow, H., Hyman, B.T., Jack, C.R., Kawas, C.H. Klunk, W.E., Koroshetz, W.J., Manly, J.J., Mayeux, R., Mohs, R.C., Morris, J.C. Rossor, M.N., Scheltens, P., Carrillo, M.C., Thies, B., Weintraub, S., Phelps, C.H. 2011. The diagnosis of dementia due to Alzheimer's disease: Recommendations from the National Institute on Aging-Alzheimer's Association workgroups on diagnostic guidelines for Alzheimer's disease. Alzheimers Dement. 7, 263-269.

Meyer, P.-F., Savard, M., Poirier, J., Labonté, A., Rosa-Neto, P., Weitz, T.M., Town, T., Breitner, J., Alzheimer's Disease Neuroimaging Initiative, PREVENT-AD Research Group, 2018. Bi-directional association of cerebrospinal fluid immune markers with stage of Alzheimer's Disease Pathogenesis. J. Alzheimers Dis. 63, 577-590.

Michaud, J.-P., Rivest, S., 2015. Anti-inflammatory signaling in microglia exacerbates Alzheimer's disease-related pathology. Neuron 85, 450-452.

Minett, T., Classey, J., Matthews, F.E., Fahrenhold, M., Taga, M., Brayne, C., Ince, P.G., Nicoll, J.A.R., Boche, D., MRC CFAS, 2016. Microglial immunophenotype in dementia with Alzheimer's pathology. J. Neuroinflammation 13, 135.

Rascovsky, K., Hodges, J.R., Knopman, D., Mendez, M.F., Kramer, J.H., Neuhaus, J., van Swieten, J.C., Seelaar, H., Dopper, E.G.P., Onyike, C.U., Hillis, A.E., Josephs, K.A., Boeve, B.F., Kertesz, A., Seeley, W.W., Rankin, K.P., Johnson, J.K., GornoTempini, M.-L., Rosen, H., Prioleau-Latham, C.E., Lee, A., Kipps, C.M., Lillo, P., Piguet, O., Rohrer, J.D., Rossor, M.N., Warren, J.D., Fox, N.C., Galasko, D., Salmon, D.P., Black, S.E., Mesulam, M., Weintraub, S., Dickerson, B.C., DiehlSchmid, J., Pasquier, F., Deramecourt, V., Lebert, F., Pijnenburg, Y., Chow, T.W. Manes, F., Grafman, J., Cappa, S.F., Freedman, M., Grossman, M., Miller, B.L., 2011. Sensitivity of revised diagnostic criteria for the behavioural variant of frontotemporal dementia. Brain 134, 2456-2477.

Rentzos, M., Zoga, M., Paraskevas, G.P., Kapaki, E., Rombos, A., Nikolaou, C. Tsoutsou, A., Vassilopoulos, D., 2006. IL-15 is elevated in cerebrospinal fluid of patients with Alzheimer's Disease and frontotemporal dementia. J. Geriatr. Psychiatry Neurol. 19, 114-117.

Scheltens, P., Blennow, K., Breteler, M.M.B., de Strooper, B., Frisoni, G.B., Salloway, S., Van der Flier, W.M., 2016. Alzheimer's disease. Lancet 388, 505-517.

Sjogren, M., Folkesson, S., Blennow, K., Tarkowski, E., 2004. Increased intrathecal inflammatory activity in frontotemporal dementia: pathophysiological implications. J. Neurol. Neurosurg. Psychiatry 75, 1107-1111.

Sochocka, M., Diniz, B.S., Leszek, J., 2017. Inflammatory response in the CNS: Friend or Foe? Mol. Neurobiol. 54, 8071-8089.

Suárez-Calvet, M., Araque Caballero, M.Á., Kleinberger, G., Bateman, R.J., Fagan, A.M., Morris, J.C., Levin, J., Danek, A., Ewers, M., Haass, C., Dominantly Inherited Alzheimer Network, 2016. Early changes in CSF sTREM2 in dominantly inherited Alzheimer's disease occur after amyloid deposition and neuronal injury. Sci. Transl. Med. 8, 369ra178.

Tai, L.M., Ghura, S., Koster, K.P., Liakaite, V., Maienschein-Cline, M., Kanabar, P., Collins, N., Ben-Aissa, M., Lei, A.Z., Bahroos, N., Green, S.J., Hendrickson, B., Van Eldik, L.J., LaDu, M.J., 2015. APOE-modulated A $\beta$-induced neuroinflammation in Alzheimer's disease: current landscape, novel data, and future perspective. J. Neurochem. 133, 465-488.

Taipa, R., Ferreira, V., Brochado, P., Robinson, A., Reis, I., Marques, F., Mann, D.M. Melo-Pires, M., Sousa, N., 2018. Inflammatory pathology markers (activated microglia and reactive astrocytes) in early and late onset Alzheimer disease: a post mortem study. Neuropathol. Appl. Neurobiol. 44, 298-313.

Taipa, R., Pinho, J., Melo-Pires, M., 2012. Clinico-pathological correlations of the most common neurodegenerative dementias. Front. Neurol. 3, 68.

Taipa, R., Sousa, A.L., Melo Pires, M., Sousa, N., 2016. Does the interplay between aging and neuroinflammation modulate Alzheimer's disease clinical phenotypes? A clinico-pathological perspective. J. Alzheimers Dis. 53, 403-417.

Teunissen, C., Menge, T., Altintas, A., Álvarez-Cermeño, J.C., Bertolotto, A., Berven, F.S., Brundin, L., Comabella, M., Degn, M., Deisenhammer, F., Fazekas, F., Franciotta, D., Frederiksen, J.L., Galimberti, D., Gnanapavan, S., Hegen, H., Hemmer, B., Hintzen, R., Hughes, S., Iacobaeus, E., Kroksveen, A.C., Kuhle, J., Richert, J., Tumani, H., Villar, L.M., Drulovic, J., Dujmovic, I., Khalil, M., Bartos, A. 2013. Consensus definitions and application guidelines for control groups in cerebrospinal fluid biomarker studies in multiple sclerosis. Mult. Scler. 19, 1802-1809.

Wang, J., Gu, B.J., Masters, C.L., Wang, Y.-J., 2017. A systemic view of Alzheimer disease - insights from amyloid- $\beta$ metabolism beyond the brain. Nat. Rev. Neurol. 13, 612-623.

Wang, W.-Y., Tan, M.-S., Yu, J.-T., Tan, L., 2015. Role of pro-inflammatory cytokines released from microglia in Alzheimer's disease. Ann. Transl. Med. 3, 136.

Westin, K., Buchhave, P., Nielsen, H., Minthon, L., Janciauskiene, S., Hansson, O. 2012. CCL2 is associated with a faster rate of cognitive decline during early stages of Alzheimer's disease. PLoS One 7, 1-6.

Zheng, C., Zhou, X.-W., Wang, J.-Z., 2016. The dual roles of cytokines in Alzheimer's disease: update on interleukins, TNF- $\alpha$, TGF- $\beta$ and IFN- $\gamma$. Transl. Neurodegener. 5, 7. 